\title{
The Relationship Between the Transactional Leadership of the Professor Perceived by the College Students of the Physical Education for Major Satisfaction, Learning Commitment, and Employment Strategy
}

\author{
Moon Soo Park ${ }^{1 *}$, Man Kyu Huh $^{2}$ \\ ${ }^{\prime}$ (Department of Physical Education, College of Art and Sports Sciences/ Dong-eui University, Korea) \\ ${ }_{2}^{2}$ (Department of Molecular Biology, College of Natural and Ecology Sciencel Dong-eui University, Korea)
}

\begin{abstract}
This study was carried out to identify the effect of styles of transactional leadership on the college students of physical education on their major satisfaction, learning commitment, and employment strategy. The research inspected the association between transactional (contingent rewards) and transformational styles of leadership influenced performance of physical education leaders such as professors or teachers. The study found no differences between boys and girls or among four grades. However, boy students were more likely to use idealized attributes and inspirational motivation, both skills of transformational leaders. It was found that the major satisfaction and the learning commitment had a significant effect on the employment strategy. The findings of this study would be useful for academic leaders. It is mainly aimed to increase the effectiveness of higher learning institution; therefore, they adopt leadership style that refines abilities of academic leaders and assists them to attain profit performance.
\end{abstract}

Keywords: Employment strategy, Learning commitment, Major satisfaction, Transactional leadership

\section{Introduction}

Transactional leadership, also known as managerial leadership, focuses on supervision, organization, and performance. Generally, the transactional and transformational theory of leadership seeks to explain the extraordinary effects that certain leaders have on their followers [1]. Transactional leadership focuses on results, conforms to the existing structure of an organization and measures success according to that organization's system of rewards and penalties. Transactional leadership is most often compared to transformational leadership. Transactional leadership depends on self-motivated people who work well in a structured, directed environment. By contrast, transformational leadership seeks to motivate and inspire workers, choosing to influence rather than direct others. It is important that college students be equipped to meet those needs and, consequently, preparation and practice for leaders address their anticipated future. Given these conditions, the current population of college students should be studied to determine the best leadership education practices necessary for development of successful leadership behavior [2].

Self-satisfaction for students is a well researched topic in both academic and non-academic (workplace) settings. In academic settings, students' satisfaction data helps colleges and universities make their curriculum more responsive to the needs of a changing marketplace [3, 4].

Our students have the opportunity to develop graduate attributes in preparation for employment, further study and participation in society. Most students like to know that their teacher is approachable. They want to be comfortable coming to him or her with a question, and they want to feel that the instructor has some interest in them as individuals.

Though there were many evidences of the positive impact of transformational leadership in followers and organizations and transformational leaders are able to articulate the organization's common purpose in a way, little is known about the cognitive aspects associated with transformational leaders that may facilitate the adoption of this leader style [5].

The purpose of the study was to examine the association of transformational and transactional professor's leadership with service physical education students' attitudes toward evidence based practices.

The research hypotheses for this are as follows. Research hypothesis 1) Sub-factors of transactional leadership conditional compensation and exceptional management will have a statistically significant effect on major satisfaction. Research hypotheses 2) Sub-factors of transactional leadership conditional reward and exceptional management will have a positive impact on learning commitment. Research hypothesis 3) Subordinate factors of transactional leadership conditional reward and exceptional management will have a static effect on employment strategy. Research hypothesis 4) Major satisfaction and learning commitment will have a positive impact on students' employment strategies (job search plan). Research hypothesis 5) Learning commitment will have a positive impact on employment strategies. 


\subsection{Population}

\section{Methods}

Students (N=211) studying at Department of Physical Education of the D. University were selected for this sample. Participants were providers of mental health clinical and case management services who took part in a larger study of organizational issues affecting the provision of mental health services to physical education students in Busan County, Korea. Table 1 shows the general characteristics of the study subjects.

Table 1. The general characteristics of the study subjects

\begin{tabular}{|l|l|l|}
\hline Categories & Groups & Frequency (\%) \\
\hline \multirow{3}{*}{ Gender } & Boy student & $145(68.76)$ \\
\cline { 2 - 3 } & Girl student & $66(31.3)$ \\
\hline \multirow{5}{*}{ Grade } & 1 Grade & $91(43.1)$ \\
\cline { 2 - 3 } & 2nd Grade & $76(36)$ \\
\cline { 2 - 3 } & 3rd Grade & $29(13.7)$ \\
\cline { 2 - 3 } & 4th Grade & $15(7.1)$ \\
\hline \multirow{4}{*}{ Admission type } & Occasional & $121(57.3)$ \\
\cline { 2 - 3 } & On time & $72(34.1)$ \\
\cline { 2 - 3 } & Admission officer & $8(3.8)$ \\
\cline { 2 - 3 } & Transfer & $6(2.8)$ \\
\cline { 2 - 3 } & Specialist & $211(100)$ \\
\hline Total & &
\end{tabular}

\subsection{Instrumentation}

\subsubsection{Measurement transactional leadership}

In order to measure transactional leadership, the questionnaire developed by Bass and Avolio [6] was modified into 10 items according to the study, and each item was composed of 5 scale (5 Likert scale) have. In addition, factor analysis of this survey tool was extracted as two outlines of conditional compensation and exceptional management. The factor loadings of conditional compensation factors were $0.626-0.777$ and exceptional management factors were $0.552-0.821$. And Cronbach's $\alpha$ coefficient is 0.813 , and overall construct validity and internal consistency of survey tool are secured.

\subsubsection{Learning commitment scale}

In order to measure the class commitment, the questionnaire developed by Schreiner and Louis [7] was reconstructed into 5 items according to the study, and each item was composed of 5 scales ( 5 Likert scale). As a result of factor analysis of this survey tool, it was extracted as a single factor and factor loading was 0.482-762. Cronbach's $\alpha$ coefficient was 0.815 . Overall, the construct validity and internal consistency of the survey tool were secured.

\subsubsection{Major satisfaction scale survey}

In order to measure the satisfaction of the major, the tools used by Billups [8] have been referred to, modified and supplemented. A total of 6 items were composed of 5 items ( 5 Likert scales). In the present study, factor analysis showed that the factor loadings were 0.652-0.751 and Cronbach's alpha coefficient was 0.945 .

\subsubsection{Employment strategies survey}

As a measure of job strategy, the questionnaire for job hunting strategy used by Kim [9] was modified to fit the study. The total score was 5 items (5-Likert scales). Factor analysis showed that the factor loadings were 0.650-809 and Cronbach's alpha coefficient was 0.789 .

\subsection{Data analysis}

Data processing of this study was performed using the SPSS 15.0 program as follows. First, to analyze demographic characteristics, frequency analysis was conducted. In order to test the validity of the measurement tools, exploratory factor analysis was performed to select the items with a standard witch of 0.4 or more. In addition, the reliability was verified by Cronbach's $\alpha$ coefficient and correlation analysis was performed to verify the correlation of measurement variables. The sub-scales have consistently demonstrated good internal consistency $(0.58 \leq \alpha \leq 0.93)$ [10]. Second, multiple regression analysis was performed on the social support system, class cohesion, and school adaptation of the subjects. The statistical significance level was set to $\alpha=$ 0.05 .

\subsection{Correlation analysis}

\section{Results and discussion}

Pearson's ratio metric correlation coefficient was calculated to confirm the relationship between measurements. As Table 2 shows, the results of this study suggest that there are no factors beyond the criterion of multi-colinearity between the factors, and therefore the absolute value of the correlation coefficients between the explanatory variables used in this study is not large. Generally, static correlation was shown. 
Table 2. Bivariate correlation coefficient for each factor

\begin{tabular}{|c|c|c|c|c|c|c|c|c|}
\hline Variable & $\mathrm{M}$ & $\mathrm{SD}$ & 1 & 2 & 3 & 4 & 5 & 6 \\
\hline 1. Total transactional leadership & 3.30 & 0.52 & - & & & & & \\
\hline 2. Conditional compensation & 3.37 & 0.64 & $0.902^{* *}$ & - & & & & \\
\hline 3. Exceptional management & 3.20 & 0.61 & $0.736^{* *}$ & $0.371^{\text {** }}$ & - & & & \\
\hline 4. Major satisfaction & 3.55 & 0.68 & $0.623^{* *}$ & $0.669^{* *}$ & $0.290^{* *}$ & - & & \\
\hline 5. Learning commitment & 3.48 & 0.61 & $0.550^{* *}$ & $0.593^{* *}$ & $0.253^{* *}$ & $0.653^{* *}$ & - & \\
\hline 6. Employment strategy & 3.53 & 0.49 & $0.524^{* *}$ & $0.520^{* *}$ & $0.309^{\text {** }}$ & $0.452^{* * *}$ & $0.474^{\text {** }}$ & - \\
\hline
\end{tabular}

\subsection{Relationship between transactional leadership and major satisfaction}

The multiple regression analysis was conducted to examine the effects of the transactional leadership of the perceived professor by the college students on physical education on their major satisfaction. The results of the multiple regression analysis were as follows. First, as shown in Table 3, the fit of the regression line showed that the transactional leadership was related to the satisfaction of the major F4 $=84.827, \mathrm{p}<0.001$ ), and $\mathrm{R} 2=0.449(44.9 \%)$ of the decision coefficients. Specifically, it was found that conditional satisfaction $(\beta=$ $0.651)$ and exceptional management $(\beta=0.049)$ were influenced by major satisfaction.

Table 3. The effect of transactional leadership on major satisfaction

\begin{tabular}{|l|l|l|l|}
\hline \multirow{2}{*}{ Variable } & Major satisfaction & $\beta$ & $\mathrm{t}$ \\
\cline { 2 - 4 } & $\mathrm{B}$ & & $4.591^{* * *}$ \\
\hline Constant & 1.036 & .651 & $11.742^{* * *}$ \\
\hline Conditional compensation & .694 & .049 & $5.026^{*}$ \\
\hline Exceptional management & .054 & \\
\hline $\mathrm{F}$ & $84.827 * * *$ & \\
\hline$R^{2}$ & .449 & \multicolumn{3}{l}{} \\
\hline$* p<0.05, * * * p<0.001$. &
\end{tabular}

\subsection{Relationship between transactional leadership and learning commitment}

The multiple regression analysis was conducted to investigate the influence of the transactional leadership of the professor perceived by the college students in the physical education on the learning commitment. The results of this study are as follows. First, the results of the multiple regression analysis were used to examine the effects of the transactional leadership of the professor perceived by the physical education college students on the learning commitment. F4 $=56.798, p<0.001$ ), and R2 =0.353, which accounts for $35.3 \%$. Specifically, it is shown that conditional compensation $(\beta=0.579)$ is not effective for learning commitment, whereas exception management has no significant effect on learning commitment.

Table 4. The effect of transactional leadership on learning commitment

\begin{tabular}{|l|l|l|l|}
\hline \multirow{2}{*}{ Variable } & \multicolumn{3}{|l|}{ Learning commitment } \\
\cline { 2 - 4 } & $\mathrm{B}$ & $\beta$ & $\mathrm{t}$ \\
\hline Constant & 1.477 & & $6.686^{* * *}$ \\
\hline Conditional compensation & 0.558 & 0.579 & $9.647^{* * *}$ \\
\hline Exceptional management & 0.038 & 0.038 & 0.629 \\
\hline $\mathrm{F}$ & $56.798^{* * *}$ & \\
\hline$R^{2}$ & 0.353 & \\
\hline$* * * p<0.001$. & \multicolumn{3}{|l}{} \\
\hline
\end{tabular}

\subsection{Transactional leadership is related to employment strategy (job search) relationship}

The multiple regression analysis was conducted to investigate the influence of the transactional leadership multiple regression analysis was conducted to examine the influence of the professors' transactional leadership on the employment strategy perceived by the college students of the physical education department. The results of this study are as follows. First, there was a significant difference between the two groups. First, there was a significant difference between the two groups. F4 = 41.590, $p<0.001$ ), and R2 $=0.287$, which accounts for $28.7 \%$ of the decision coefficients. Specifically, it was found that employment strategy affected conditional compensation $(\beta=0.470)$ and exceptional management $(\beta=0.137)$.

Table 5. Effect of transactional leadership on employment strategy

\begin{tabular}{|l|l|l|l|}
\hline \multirow{2}{*}{ Variable } & Job strategy & $\beta$ & $\mathrm{t}$ \\
\cline { 2 - 4 } & $\mathrm{B}$ & & $10.540^{* * *}$ \\
\hline Constant & 1.961 & 0.470 & $7.446^{* * *}$ \\
\hline Conditional compensation & 0.362 & 0.137 & $2.163^{*}$ \\
\hline Exceptional management & 0.110 & \\
\hline $\mathrm{F}$ & $41.590 * * *$ & \\
\hline$R^{2}$ & 0.287 & \multicolumn{2}{l}{} \\
\hline$* p<0.05, * * * p<0.001$. &
\end{tabular}




\subsection{Major satisfaction and relationships between learning commitment and employment strategy}

The multiple regression analysis was conducted to examine the influence of the major satisfaction and the learning commitment on the employment strategy. As shown in Table 6, when the fit of the regression line was tested, it was found that the major satisfaction and the learning commitment had a significant effect on the employment strategy $(\mathrm{F} 4=36.399, p<0.001)$. The coefficient of determination is $\mathrm{R} 2=0.260$, which accounts for $26.0 \%$. Specifically, the major satisfaction was found to affect the employment strategy $(\beta=0.250)$ and the learning commitment $(\beta=0.311)$.

Table 6. Effects of major satisfaction and learning commitment on employment strategy

\begin{tabular}{|l|l|l|l|}
\hline \multirow{2}{*}{ Variable } & Job strategy & $\beta$ & $\mathrm{t}$ \\
\cline { 2 - 4 } & $\mathrm{B}$ & & $11.324 * * *$ \\
\hline Constant & 36.399 & 0.250 & $3.172^{* *}$ \\
\hline Conditional compensation & 0.180 & 0.311 & $3.946^{* * *}$ \\
\hline Exceptional management & 0.249 & & \\
\hline $\mathrm{F}$ & $36.399 * * *$ & \\
\hline$R^{2}$ & 0.260 & \multicolumn{3}{l|}{} \\
\hline$* p<0.05, * * * p<0.001$. &
\end{tabular}

Transformational-transactional leadership theory dominates current thinking about leadership research [11]. The extant leadership literature provides little guidance on transactional leadership development. This may stem from the fact that most leaders do not need development to behave transactionally with their followers [12]. Transactional leadership is traditional leadership [13]. As Weber [14] indicated, a system of operation and coordination is called "traditional" if it is part of an existing system of control, and if the leader enjoys authority based on status and on the existence of personal loyalty created through a process of education [12]. This creative process of education needs can lead to the development of leadership. Real-world examples, employment strategy, and on-the-job training opportunities abound for the leader attempting to develop their transactional leadership behaviors. This study concerns the alignment of transactional and transformational leadership within the realm of sport education. In part, the research discusses how transformational leadership augments transactional skills [15]. The research was aimed particularly at looking for the use of transformational leadership skills within the world of sport coaching.

\section{Conclusion}

Although this study did not confirm all the hypothesized relationships between transformational leadership, major satisfaction, learning commitment, and employment strategy, an important insight was gained into the positive effects and transactional leadership had played in this context. The positive relationship between transactional leadership, conditional compensation and exceptional management implies the importance of perceived fairness in the outcome of a reward.

\section{References}

[1] B.M. Bass, Bass \& Stogdill's Handbook of Leadership (3rd ed.), New York, Free Press, 1990

[2] K. Rosenbusch, and C. Townsend, The relationship of gender and organizational setting to transformational and transactional leadership skills of selected college student leaders, Journal of Leadership Education,3, 2004, 4-20.

[3] R. Eyck, M. Tews, and J.M. Ballester, Improved Medical Student Satisfaction and Test Performance With a Simulation-Based Emergency Medicine Curriculum: A Randomized Controlled Trial, Chicago, IL, 2009.

[4] L. Witowski, The relationship between instructional delivery methods and students learning preferences: What contributes to students' satisfaction in an online learning environment? Ph.D., Dissertation, 2008.

[5] Y.A.N. Ling, Z. Simsek, M.H. Lubatkin, and J.F. Veiga, Transformational leadership's role in promoting corporate entrepreneurship: Examining the CEO-TMT interface. Academy of Management Journal, 51(3), 2008, 557-576.

[6] B.M. Bass, and B.J. Avolio, MLQ Multifactor Leadership Questionnaire: Technical report, Redwood City, CA: Mind Garden, Inc., 1995.

[7] L. Schreiner, and M. Louis, Measuring engaged learning in college students: Beyond the borders of NSSE. Paper presented at the annual meeting of the Association for the Study of Higher Education, Anaheim, CA, 2006.

[8] F.D. Billups, Measuring College Student Satisfaction: A Multi-Year Study of the Factors Leading to Persistence, NERA Conference Proceedings, 2008, 14.

[9] H.S. Kim, A Study on the Effect of Employability Perception of University Student on Employment Strategies, Master, Kyonggi University, 2014.

[10] D.N.D, Hartog, and J.J. Van Muijen, Transactional versus transformational leadership: An analysis of the MLQ. Journal of Occupational \& Organizational Psychology, 70 (1), 1997, 19-35.

[11] T.A. Judge, and R.F. Piccolo, Transformational and transactional leadership: A meta-analytic test of their relative validity. Journal of Applied Psychology, 89(5), 2004, 755-768.

[12] J.A. McCleskey, Situational, Transformational, and Transactional Leadership and Leadership Development. Journal of Business Studies Quarterly, 5(4), 2014, 117-130.

[13] J.M. Burns, Leadership, New York, NY: HarperCollins, 1978

[14] M. Weber, The theory of social and economic organization (T. Parsons Trans.). New York, NY: Free Press, 1947 (Original work published in 1924).

[15] J. Rowold, Transformational and Transactional Leadership in Martial Arts. Journal of Applied Sport Psychology, 18 (4), $2006,312-$ 325. 